\title{
GASTRINOMA PRIMÁRO DE FÍGADO
}

\author{
PRIMARY LIVER GASTRINOMA
}

\section{Antônio Carlos Valezi , TCBC-PR ${ }^{1}$ José Guilherme Vartanian, RCBC-PR ${ }^{2}$}

\section{INTRODUÇÃO}

Os gastrinomas foram descritos em 1955 por Zollinger-Ellison ${ }^{1}$. São tumores neuroendócrinos do pâncreas que se caracterizam pela produção anômala de gastrina. Mostram comportamento maligno em mais de $60 \%$ dos casos, e em $50 \%$ das vezes já apresentam metástases ao diagnóstico, a maioria para linfonodos e fígado ${ }^{2}$. Localiza-se preferencialmente no pâncreas, duodeno e linfonodos, dentro do chamado "triângulo dos gastrinomas". Em 5\% dos casos localiza-se no fígado, estômago, ovário, rim, paratireóide, omento, jejuno e coração ${ }^{3}$. Nestes pacientes, ao contrário dos que apresentam tumores na localização usual, os gastrinomas apresentam menores taxas de metastatização e maior chance de cura com a ressecção cirúrgica ${ }^{4}$.

\section{RELATO DO CASO}

Paciente do sexo masculino, quinze anos, branco, procurou serviço médico em 1994. Apresentava queixas de epigastralgia desde há dois anos. Endoscopia digestiva alta diagnosticou esofagite, gastrite e úlcera duodenal (A2 -Sakita). A dosagem de gastrina sérica mostrou-se elevada, $5610 \mathrm{pg} / \mathrm{ml}$ (normal até $160 \mathrm{pg} / \mathrm{ml}$ ). Os exames de ultrassonografia (USG) e tomografia axial computadorizada (TAC) de abdome, evidenciaram nódulo hepático sólido, em lobo direito, de 5,7 cm no seu maior diâmetro. Realizada biópsia por laparoscopia, com resultado inconclusivo (área focal de fibrose, com infiltrado mononuclear portal discreto ). Optou-se por tratamento clínico com inibidor de bomba de prótons.
Após dois anos de tratamento irregular, continuava com as queixas descritas anteriormente. Nova endoscopia digestiva demonstrou úlceras esofágica e duodenal (H2 - Sakita). Dosagem de gastrina sérica, sem estímulo, de 22000 pg/ml. USG e TAC abdominais evidenciaram nódulo hepático de $9,5 \mathrm{~cm}$ de diâmetro em lobo direito (Figura 1). Realizada arteriografia digital seletiva hepática e pancreática, que demonstraram tumor hipervascularizado em lobo hepático direito, com pâncreas normal. Alfafetoproteína com valor normal, e ausência de indícios clínicos e laboratoriais de NEM-I. Instituido tratamento cirúrgico. No intra-operatório, foi realizado ultrassonografia do pâncreas e transiluminação endoscópica do duodeno, ambas com resultados normais. Realizada biópsia de congelação do nódulo hepático que sugeriu tumor carcinóide, realizada hepatectomia direita.

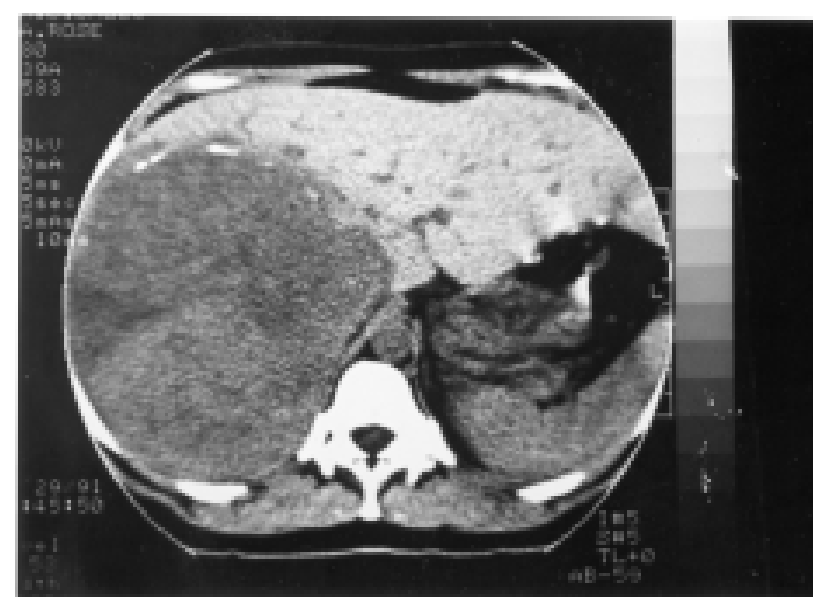

Figura 1 - Tomografia de abdome evidenciando nódulo hepático de 9,5 cm de diâmetro em lobo direito.

1. Professor Adjunto Doutor do Departamento de Cirurgia da Universidade Estadual de Londrina.

2. Ex-residente de Cirurgia Geral do Departamento de Cirurgia da Universidade Estadual de Londrina. 
Exame anátomo-patológico e imunohistoquímico da peça operatória confirmou tratar-se de gastrinoma. O controle sérico da gastrina no quarto e décimo-quinto dia de pós-operatório mostraram níveis de 47 e 65 $\mathrm{pg} / \mathrm{ml}$ respectivamente.

Atualmente, cinco anos após o tratamento cirúrgico, o paciente mantém-se assintomático e com níveis de gastrina dentro da normalidade.

\section{DISCUSSÃO}

A incidência dos gastrinomas varia de 0,1 a 3 casos por milhão de habitantes, respondendo por 0,1 a1\% dos pacientes com doença ulcerosa ${ }^{5}$. Em aproximadamente $20 \%$ dos casos estão associados a NEM-I 5 .

Para o diagnóstico, a dosagem da gastrina sérica durante jejum é o melhor método de rastreamento, com positividade de mais de $99 \%$ nos pacientes com Síndrome de Zollinger-Ellison ${ }^{5}$. A verificação de aumento da secreção ácida gástrica basal e a positividade de testes provocativos (principalmente com o teste de estimulação com secretina) ajudam a confirmar o diagnóstico. No caso descrito, os sintomas persistentes sem resposta satisfatória à terapêutica clínica, associada a níveis extremamente elevados de gastrina sérica, com resposta positiva ao teste de estimulação com refeição padrão, confirmaram o diagnóstico da doença.

A localização preferencial destes tumores se faz no pâncreas, duodeno e linfonodos, dentro do chamado "triângulo dos gastrinomas", delimitado pela união do ducto cístico e colédoco superiormente, segunda e terceira porções do duodeno lateralmente, e junção do colo e corpo do pâncreas medialmente. A ocorrência extra-pancreaticoduodenal e linfonodal é rara $^{3}$.Em todos os casos, a identificação topográfica pré-operatória e a presença de metástases, são fundamentais para o planejamento terapêutico.Mesmo com a realização de exames de imagens, em 50\% dos casos, os gastrinomas não são detectados no préoperatório. Na cirurgia consegue-se identificar os tumores em mais de $90 \%$ das vezes ${ }^{3,5}$.

Os estudos como ultrassonografia, tomografia computadorizada, ressonância magnética e a angiografia, apresentam sensibilidade ao redor de 50-60\% para os tumores primários, e um pouco maior na detecção de metástases $(80-85 \%)^{5}$.As dosagens hormonais através de amostras de sangue portal, acabam por regionalizar a hiperssecreção de gastrina em detrimento da localização propriamente dita ${ }^{5}$. O ultrassom endoscópico e a cintilografia para receptores da somatostatina, métodos não invasivos, tem sensibilidade ao redor de $93 \%{ }^{3}$. A localização pré-operatória é fundamental para a elaboração da estratégia do tratamento. No paciente citado, pelo tamanho e extensão do tumor, sua detecção não foi dificil, tendo sido demonstrado já no USG de abdome. A utilização dos demais métodos disponíveis se fez necessário em virtude da elevada freqüência de metástases hepáticas que ocorrem nos gastrinomas, sendo o fígado e linfonodos os principais sítios de metastatização ${ }^{3}$.

Com o uso dos inibidores da bomba de prótons, a adoção de gastrectomias para o controle da doença, como antigamente preconizado, não se faz mais necessário ${ }^{4}$. A preocupação recai no controle da natureza maligna dos gastrinomas, demonstrando-se que a ressecção cirúrgica altera a história natural da doença, com menores taxas de metástases e melhor sobrevida quando comparados aos pacientes submetidos a tratamento clinico ${ }^{4}$.

A ressecção do tumor ainda permanece a única arma para a potencial cura, devendo ser realizada em todos os pacientes com doença localizada e naqueles com metástases consideradas ressecáveis. Como nem todos os tumores são localizados no préoperatório, e também podem apresentar metástases não identificáveis antes da cirurgia, a exploração cirúrgica deve ser padronizada e rigorosa, com inspeção visual e palpatória minuciosas, realização de ultrassonografia no intra-operatório, endoscopia digestiva para transiluminação duodenal, e como preconizado por alguns autores, duodenotomia e exploração digital local. Com esta padronização, aliada aos métodos descritos no pré-operatório, o achado se faz em 90-92\% dos casos ${ }^{3,5}$. Nos gastrinomas considerados irressecáveis, o uso de quimioterapia e hormonioterapia podem trazer algum benefício. Outras opções são a embolização, imunoterapia com interferon alfa e o transplante hepático ${ }^{4}$.

Com base nestes dados, o doente foi submetido ao tratamento cirúrgico, não tendo sido evidenciados sinais de outras lesões, após rigorosa avaliação intra-operatória, favorecendo a suspeita de tumor primário hepático.

Associando os achados antes, durante e após a operação ao seguimento de cinco anos, com cura clínica e bioquímica do paciente, consideramos tratar-se de gastrinoma hepático primário, fato raramente demonstrado na literatura. 


\begin{abstract}
Gastrinomas are generally localized in pancreas, duodenum and lymphonodes, within the so called "gastrinoma's triangle". In 5\% of the cases, it may arise from liver, stomach, ovarium, kidneys, parathyroid, omentum, jejunum and heart. We describe a case of a fifteen-year-old boy with a primary gastrinoma of the liver, treated by right-hepatectomy.
\end{abstract}

Key Word: Gastrinoma; Zollinger-Ellison syndrome; Liver; Surgery; Hepatectomy; Carcinoid tumor.

\section{REFERÊNCIAS}

1. Zollinger RM, Ellison EH - Primary peptic ulcerations of the jejunum associated with islet cell tumors of the pancreas. Ann Surg, 1955, 142:709-728.

2. Wolfe MM, Alexander RW, McGuigan JE Extrapancreatic, extraintestinal gastrinoma: effective treatment by surgery. N Engl J Med, 1982, 306(25):15331536.

3. Wu PC, Alexander HR, Bartlett DL, et al. - A prospective analysis of the frequency, location, and curability of ectopic (nonpancreaticoduodenal, nonnodal) gastrinoma. Surgery, 1997, 122(6):1176-1182.
4. Norton JA, Doherty GM, Fraker DL, et al. - Surgical treatment of localized gastrinoma within the liver: a prospective study. Surgery, 1998, 124(6):11451152.

5. Meko JB, Norton JA - Management of patients with Zollinger-Ellison syndrome. Annu Rev Med, 1995, 46: 395-411.

Endereço para Correspondência Antonio Carlos Valezi Rua Santos 777 apto 1302 86020-021 Londrina - PR valezi@sercomtel.com.br 